\title{
ВОПРОСЫ КОНКУРЕНЦИИ НОРМ УСТАНАВЛИВАЮЩИХ АДМИНИСТРАТИВНУЮ ОТВЕТСТВЕННОСТЬ ЗА НАРУШЕНИЕ ЗАКОНОДАТЕЛЬСТВА О БАНКАХ И БАНКОВСКОЙ ДЕЯТЕЛЬНОСТИ
}

\begin{abstract}
Аннотация. Предметом исследования являются научные знания, теоретические пред-ставления о состоянии и путях дальнейщего развития общественных отноше-ний, складывающихся в сфере установления и применения норм утанавливающих административную ответственность кредитных организаций за нарушение действующего законодательства регулирующего осуществление банковской деятельности, включая пруденциальных требований Центрального банка России. В статье подвергаются анализу отдельные проблемы, вызванные дуализмом закрепления санкционных мер воздействия в Кодексе Российской Федерации об административных правонарушениях и в нормах банковского права. Основываясь на теоретических исследованиях, а так же практике применения указанных норм приведены соответствующие выводы и предложения по устранению выявленной проблеме. Методологической основой исследования являются современные методы научного познания общественных и правовых закономерностей, сравнительно-правовой, системноструктурный, формально-юридический, а также системный анализ, при написании статьи был использован системный подход и другие частнонаучные методы исследования. Научная новизна работы определяется как самой постановкой проблемы, так и подходом к ее исследованию с учетом недостаточной степени ее разрабо-танности. Разрешение указанной коллизии возможно путем исключения п.1 $14.1 \mathrm{~cm} .74$ Федерального закона «О Центральном банке...» и изменения ст. 15.26 КоАП РФ в предложеной редакции.

Ключевые слова: административная ответственность, итраф, обязательные нормативы, банковская деятельность, Банк России, пруденциальные требования, банковское законодательство, предупреждение, принуждение, административно-правовое регулирование.

Abstract. The article focuses on the scientific knowledge and theoretical ideas about the condition and the ways of further development of social relations, arising in the sphere of imposition of administrative liability of lending agencies for the violation of current legislation on banking, including prudential requirements of the Central Bank of Russia. The author analyzes particular problems, caused by the dualism of sanctions in the Code of Administrative Offences and banking law of the Russian Federation. On the basis of theoretical researches and the practice of the mentioned norms application, the author formulates conclusions and proposals for the revealed problem elimination. The methodology of the research is based on the modern methods of scientific cognition, including the comparativelegal, the system-structural and the formal-legal methods and the systems analysis, the systems approach and other special scientific research methods. The novelty of the research is defined by the very formulation of the problem and the approach to its solving, taking into account that it hasn't been sufficiently studied. This collision can be solved provided that the clause 1, part 1 of the article 74 of the Federal Law "On the Central Bank..." is excluded, and the article 15.26 of the Code of Administrative Offences is changed according to the author's proposals.
\end{abstract}

Key words: administrative liability, fine, compulsory standards, banking, Bank of Russia, prudential requirements, banking law, warning, coercion, administrative-legal regulation.

$\mathrm{O}$ траслевое банковское законодательство предусматривает необходимость соблюдения кредитными организациями действующего законодательства, экономических (финансовых) нормативов в целях обеспечения собственной стабильности и надежности. При достижении указанной цели достигается стабильность и надежность всей банковской системы, что собственно является целью деятельности ЦБ РФ (ст.3 Закона «0 Центральном банке Российской Федерации (Банке России)») [2]. Банк России, является органом банковского регулирования и банковского надзора (ст.56) [2], что выражается в нормативном установлении правил проведения банковских операций, осуществления расчетов, пруденциальные требования и т.д., а так же проверяет как выполняются установленные законами и нормативными актами требования кредитными организациями.

Нарушение норм кредитными организациями отслеживается Центральным банком России и неизбежно влечет за собой применение ответственности. Подробнее хочется остановиться на административно-правовой ответственности кредитной организации за допущенное нарушение. 
Ученые - правоведы, а в частности А. Л. Прозоров [14, С. 405], выделяют предупредительные и принудительные меры воздействия за нарушение пруденциальных норм деятельности. Они предусмотрены Инструкцией Банка России № 59 «0 применении к кредитным организациям мер воздействия» [3] (далее - Инструкция), которая разъясняет вопросы и особенности применения этих мер воздействия за выявленные нарушения в деятельности к кредитным организациям и их филиалам. Приведены размеры штрафов и иные меры административно-правового воздействия, применяемые к кредитным организациям за нарушение норм регулирующих банковскую деятельности. Причем, А. Л. Прозоров, не исследует правовую сущность применяемых ЦБ РФ мер, а рассматривает этот вопрос через призму правового статуса Банка России и непосредственно через реализацию им государственно-властных полномочий в отношении кредитных организаций. А например, М. В. Карасева [12, С. 37], говорит напротив, что отношения по установлению обязательных нормативов диктуемых пруденциальными нормами, так же надзору за их деятельностью нельзя считать финансово-правовыми и включать в предмет финансового права.

Проблема в определении правовой сущности и вида ответственности за нарушение пруденциальных норм, как указывает Надежин Н. Н., не предоставляет возможности определить правовую природу пруденциальных санкций [13, С. 205].

Однако, надзорная деятельность осуществляемая ЦБ РФ, предполагает не только выявление нарушений (угроз), но и своевременное применение мер, направленных на их предупреждение и пресечение.

В частности, согласно упомянутой ранее Инструкции, надзорные органы применяют к кредитным организациям меры воздействия двух типов:

- предупредительные;

- принудительные.

Выбор мер воздействия, по общему правилу, производится надзорными органами самостоятельно исходя из положений нормативных актов с учетом:

- характера допущенных кредитной организацией нарушений;

- причин, обусловивших возникновение выявленных нарушений;

- общего финансового состояния кредитной организации.

- положения кредитной организации на федеральном и региональном рынке банковских услуг.

Случаи, при которых Инструкция предписывает применять предупредительные меры воздействия, можно условно разделить на 3 группы (п. 1.7):
1) случаи допущения незначительных нарушений обязательных нормативов, некоторых требований федеральных законов и актов Банка России (не угрожающих финансовому состоянию кредитной организации, не затрагивающих интересы ее вкладчиков и кредиторов);

2) случаи ухудшения показателей деятельности кредитной организации при отсутствии нарушения обязательных нормативов или иных требований, определяющих предельные уровни рисков, принимаемых кредитной организацией;

3) случаи, когда имеются признаки, свидетельствующие об опасности ухудшения финансового состояния кредитной организации.

Содержание предупредительных мер воздействия включает (п. 1.9 Инструкции):

- доведение до органов управления кредитной организации информации о недостатках в ее деятельности и об обеспокоенности надзорного органа состоянием дел в кредитной организации;

- $\quad$ изложение рекомендаций надзорного органа по исправлению создавшейся в кредитной организации ситуации;

- $\quad$ предложения представить в надзорный орган программу мероприятий, направленных на устранение недостатков, включая при необходимости обязательства, принимаемые на себя кредитной организацией, ее учредителями (участниками).

- установление дополнительного контроля за деятельностью кредитной организации и за выполнением ею мероприятий по нормализации деятельности.

Характер указанных мер свидетельствует, что они действительно не носят принудительного характера и являются разновидностью административных методов убеждения.

Согласно п. 1.5 Инструкции, указанные меры могут применяться при условии ответственного, конструктивного подхода органов управления, а в соответствующих случаях и учредителей (участников) кредитной организации к устранению нарушений в ее деятельности, а также при условии надлежащего взаимодействия кредитной организации и ее учредителей (участников) с надзорными органами. Взаимодействие с надзорными органами должно выражаться в принятии кредитной организацией, а в необходимых случаях и ее учредителями (участниками) соответствующих обязательств по корректировке деятельности данной кредитной организации. Причем, несмотря на употребление в данном случае термина «обязательство», очевидно, что речь идет лишь об обещаниях, не имеющих юридической силы. 


\section{Административное и муниципальное право 1 (97) 2016}

Основаниями для применения принудительных мер воздействия являются нарушения (невыполнение) кредитной организацией требований федеральных законов, регулирующих банковскую деятельность нормативных актов и предписаний Банка России, непредставление информации, представление неполной или недостоверной информации, а также в случае, если совершаемые кредитной организацией операции создали реальную угрозу интересам клиентов и/или кредиторов (вкладчиков) (п. 1.14 Инструкции).

К этим мерам инструкция относит (п. 1.15):

1) штрафы.

В данном случае имеются в виду штрафы, предусмотренные ст. 74 Федерального закона «0 Центральном банке...», взимаемые в размере до 0,1\% минимального размера уставного капитала, а в случаях неисполнения в установленный срок предписаний Банка России об устранении нарушений, выявленных в деятельности кредитной организации, и в случаях, если нарушения или совершаемые кредитной организацией банковские операции или сделки создали реальную угрозу интересам ее кредиторов (вкладчиков), до $1 \%$ размера оплаченного уставного капитала, но не более $1 \%$ минимального размера уставного капитала;

2) требование об осуществлении кредитной организацией мероприятий по ее финансовому оздоровлению, в том числе включая требование о предоставлении и выполнении плана мер по финансовому оздоровлению;

3) требование о приведении в соответствие величины собственных средств (капитала) и размера уставного капитала кредитной организации в соответствие с п. 2 ст. 12 Федерального закона «0 несостоятельности (банкротстве) кредитных организаций» (Прим. автора: указанный закон утратил силу, однако, данное положение не приведено в соответствии с действующим законодательством);

4) требование о реорганизации кредитной организации, в том числе включая требование о предоставлении и выполнении плана мероприятий по реорганизации;

5) ограничение проведения кредитными организациями отдельных операций на срок до шести месяцев;

6) запрет на осуществление кредитными организациями банковских операций, предусмотренных выданной лицензией, на срок до одного года;

7) запрет на открытие филиалов на срок до одного года;

8) требование о замене руководителей кредитной организации;

9) назначение Временной администрации по управлению кредитной организацией;
10) отзыв лицензии на осуществление банковских операций.

Применяемые к кредитной организации принудительные меры воздействия, как правило, оформляются в виде предписания (п. 1.16).

Правовая природа указанных принудительных мер достаточно дискуссионна. Ряд авторов считают эти меры мерами «финансово-правового принуждения». Так, по мнению А. 3. Арсланбековой, «...это самостоятельные меры финансовоправового принуждения, так как они отличаются от мер административного принуждения сферой применения. Целью использования мер принуждения в банковской сфере является регулирование деятельности кредитной организации при осуществлении ЦБ РФ функций банковского регулирования и банковского надзора. В свою очередь, отношения, связанные с банковским регулированием и надзором, относятся к предмету финансового права и защищаются мерами финансово-правового принуждения» [8].

Поскольку утверждение, что отношения, связанные с банковским регулированием и надзором, относятся к предмету финансового права, является неверным, представляется очевидным, что все перечисленные меры (и ряд других, которые предусмотрены банковским законодательством), представляют собой меры административного принуждения, которые в теории административного права, начиная с 60-х годов прошлого столетия принято делить на меры предупреждения, пресечения и взыскания (ответственности) [11, С. 61-67]. При этом все эти меры (кроме штрафа и отзыва лицензии) можно охарактеризовать как меры предупреждения или пресечения (в зависимости от цели и оснований применения).

Что касается штрафа, предусмотренного ст. 74 Федерального закона «О Центральном банке...», то он, безусловно, представляет собой наказание - меру юридической ответственности. Рассматривать его как вид финансово-правовой ответственности, на наш взгляд, нет никаких оснований. Многие авторы, в частности, И. И. Веремеенко вообще подвергают сомнению выделение финансово-правовой ответственности в особый вид юридической ответственности. Он отмечает: «пожалуй, только специфика процессуального порядка реализации рассматриваемых мер в определенной степени является их особенностью. Но и это обстоятельство их исключительной особенностью не является, ибо и в административном и в других отраслях права ряд санкций реализуется в особом процессуальном порядке» [9, С. 43].

И в данном ключе следует отметить, что ст. 15.26 КоАП РФ [1] также предусматривает ответственность в виде штрафа за нарушение законода- 
тельства о банках и банковской деятельности, причем в значительно меньшем размере:

- $\quad$ за нарушение, выразившееся в осуществлении кредитной организацией производственной, торговой или страховой деятельности - от сорока до пятидесяти тыс. руб. (ч. 1 ст. 15.26);

- за нарушение кредитной организацией установленных Банком России нормативов и иных обязательных требований - от десяти до тридцати тыс. руб. (или предупреждение) (ч. 2 ст. 15.26);

- $\quad$ за нарушения, предусмотренные ч. 2 ст. 15.26, если они создают реальную угрозу интересам кредиторов (вкладчиков), - от сорока до пятидесяти тыс. руб.

При этом рассмотрение дел о данных административных правонарушениях КоАП РФ возложил на мировых судей, составление протоколов - на служащих Банка России. Таким образом, возникла коллизия норм об ответственности, которая до сих пор не разрешена.

В Указании оперативного характера от 2 июля 2002 г. № 84-Т «0 Кодексе Российской Федерации об административных правонарушениях» [4], разъясняя порядок применения ст. 15.26 КоАП РФ, Банк России отметил, что данная норма не выделяет специальных субъектов административной ответственности и позволяет применять административные наказания, как к кредитным организациям, так и к их должностным лицам. Поэтому Банк России рекомендовал своим территориальным учреждениям возбуждать дела об административных правонарушениях, установленных ст. 15.26 КоАП РФ, лишь в отношении должностных лиц кредитных организаций, а к самим кредитным организациям применять меры, предусмотренные федеральным банковским законодательством. Безусловно, такая позиция не основана на законе и по какой то причине, до сих пор документ не отменен.

Иначе разрешил данную коллизию Пленум Высшего Арбитражного Суда РФ от 27 января 2003 г. № 2 «О некоторых вопросах, связанных с введением в действие Кодекса Российской Федерации об административных правонарушениях», указав, что нормы, содержащиеся в федеральных законах и устанавливающие ответственность в сфере публичных правоотношений, не отмененные Федеральным законом «О введении в действие Кодекса Российской Федерации об административных правонарушениях» от 30 декабря 2001 г. № 196-Ф3, подлежат применению после 30 июня 2002 г. в части, не противоречащей Кодексу об административных правонарушениях (п. 1).

При этом, исходя из буквального прочтения данного пункта, не имеет значение даже то, что Федеральный закон «0 Центральном банке...» был принят позже, чем КоАП РФ. Очевидно, Высший Арбитражный Суд РФ принял во внимание, что иные законы не могут устанавливать административную ответственность, поскольку законодательство об административных правонарушениях состоит из КоАП РФ и принимаемых в соответствии с ним законов субъектов РФ (п. 1 ст. 1.1 КоАП РФ).

Тем не менее, Банк России продолжил проводить свою линию в данном вопросе. М. В. Демьянец приводит следующие данные.

Ст. 15.26 КоАП РФ в период с 2002-2009 гг. вовсе не применялась к кредитными организациям (производство по делам об административных правонарушениях, если и было начато, то прекращалось по различным основаниям). Лишь в 2010 г. впервые за 8 лет данная статья была применена к кредитной организации - было наложено административное наказание в виде административного штрафа в размере 20 тыс. руб. (12 производств прекращено, 2 - возвращено для устранения недостатков протоколов).

А в остальные периоды, как свидетельствует официальная статистика ситуация в корне не изменилась: 2010 г. из 9 принятых материалов: 5возвращено, 2- передано по подведомственности/ подсудности, 1- прекращено, 1- подвергнуто наказанию, штраф 20 тыс. руб.; 2011 г. из 3 принятых материалов: 1- передано по подведомственности/ подсудности, 2- подвергнуто наказанию, штраф 60 тыс. руб.; 2012 г. - ни одного; 2013 г. - ни одного; 2014 г. (за 6 месяцев) принято к рассмотрению - 2 дела. (Прим. автора).

За тот же период «в порядке надзора» Банком России: налагались штрафы в отношении 723 банков - 2002 г.; 595 банков - 2003 г.; 460 банков 2004 г.; 510 банков - 2005 г.; 514 банков - 2006 г;; 448 банков - 2007 г.; 351 банка - 2008 г.; 275 банков 2009 г.; 280 банков - 2010 г. [10, С. 99].

Реакция на такую позицию Банка России последовала со стороны арбитражных судов и получила свое выражение в принимаемых ими судебных актах по делам об обжаловании решений и действий Центрального банка Российской Федерации. Так, Федеральный арбитражный суд Московского округа пришел к выводу, что состав ст. 15.26 КоАП РФ поглощает состав ст. 74 Федерального закона «0 Центральном банке...», и что применение мер административной ответственности за нарушение банковского законодательства должно производиться в порядке и на основании КоАП РФ [5].

В большинстве случаев суды, как правило, приходят к выводу, что применение мер административной ответственности за нарушения банковского законодательства не может превышать размер, установленный ч. 2 ст. 15.26 КоАП РФ, и изменяют предписания Банка России в части штрафа, превышающего этот размер [6]. 
В постановлениях некоторых судов также указывается на то, что невозможность снижения размера штрафа, предусмотренного ст. 74 Федерального закона «О Центральном банке...» не позволяет применять эту меру взыскания с учетом характера совершенного правонарушения, размера причиненного вреда, степени вины правонарушителя и иных существенных обстоятельств деяния, что нарушает принципы справедливости наказания, его индивидуализации и соразмерности [7].

Позиция арбитражных судов в целом заслуживает поддержки: они однозначно признали штраф, установленный ст. 74 Федерального закона «0 Центральном банке...» административным наказанием, которое законодатель установил вопреки требованиям КоАП РФ, в ином федеральном законе. Тем не менее, окончательное разрешение данной коллизии видится в исключении п.1 ч.1 ст. 74 Федерального закона «О Центральном банке...»

На наш взгляд следует изложить ст. 15.26 КоАП РФ в следующей редакции:

1. В случае неисполнения в установленный Банком России срок предписаний Банка России об устранении нарушений, выявленных в деятельности кредитной организации, а также в случае, если эти нарушения или совершаемые кредитной организацией банковские операции или сделки создали реальную угрозу интересам ее кредиторов (вкладчиков) -

влечет наложение административного штрафа на юридическое лицо - до 1 процента размера оплаченного уставного капитала, но не более 1 процента минимального размера уставного капитала.
2. Осуществление кредитной организацией производственной, торговой или страховой деятельности -

влечет наложение административного штрафа на должностных лиц в размере от сорока тысяч до пятидесяти тысяч рублей и на юридическое лицо - до 1 процента размера оплаченного уставного капитала, но не более 1 процента минимального размера уставного капитала.

3. Нарушение кредитной организацией установленных Банком России нормативов и иных обязательных требований -

влечет предупреждение или наложение административного штрафа на должностных лиц в размере от десяти тысяч до тридцати тысяч рублей и на юридическое лицо - до 1 процента размера оплаченного уставного капитала, но не более 1 процента минимального размера уставного капитала.

4. Действия, предусмотренные частью 3 настоящей статьи, если они создают реальную угрозу интересам кредиторов (вкладчиков), -

влекут наложение административного штрафа на должностных лиц в размере от сорока тысяч до пятидесяти тысяч рублей и на юридическое лицо - до 1 процента размера оплаченного уставного капитала, но не более 1 процента минимального размера уставного капитала.

5. При повторном нарушении в отношении юридического лица могут быть применены меры воздействия установленные ст. 74 Федерального закона «0 Центральном банке...»

Примечание. Правонарушением совершенным неоднократно, признается правонарушение, если это лицо ранее привлекалось к административной ответственности за деяние установленное настоящей статьей в течение ста восьмидесяти дней.

\section{Библиография:}

1. Кодекс Российской Федерации об административных правонарушениях от 30 декабря 2001 г. № 195-Ф3 // Собрание законодательства Российской Федерации. 2002. № 1 (часть I). Ст. 1.

2. Федеральный закон от 10 июля 2002 г. № 86-Ф3 «О Центральном банке Российской Федерации (Банке России)» // Собрание законодательства Российской Федерации. 2002. № 28. Ст. 2790.

3. Приказ ЦБ Российской Федерации от 31 марта 1997 г. № 02-139 «0 введении в действие инструкции «0 применении к кредитным организациям мер воздействия за нарушения пруденциальных норм деятельности» // Вестник Банка России. 1997. № 23(186).

4. Указание оперативного характера ЦБ Российской Федерации от 2 июля 2002 г. № 84-Т «0 Кодексе Российской Федерации об административных правонарушениях» // Вестник Банка России. 2002. № 38.

5. Постановление Федерального арбитражного суда Московского округа от 28 октября 2003 г. № КА-А40/8495-03 // Судебно-арбитражная практика Московского региона. Вопросы правоприменения. 2004. № 2.

6. Постановление Федерального арбитражного суда Уральского округа от 17 ноября 2010 г. № Ф09-9362/10-С.

7. Постановление Федерального арбитражного суда Дальневосточного округа от 12 апреля 2011 г. № Ф03-9261/10.

8. Арсланбекова А.З. Соотношение финансово-правовой и административно-правовой ответственности, применяемой за нарушение банковского законодательства // Законодательство. 2010. № 1.

9. Веремеенко И.И. К вопросу о финансово-правовой и административно-правовой ответственности в российском праве // Право и управление. XXI век. 2012. № 4.

10. Демьянец М.В. Административная ответственность кредитных организаций за нарушение законодательства о банках и банковской деятельности: Монография. - М., 2011. 
11. Еропкин М.И. О классификации мер административного принуждения // Вопросы советского административного права на современном этапе. М., 1963.

12. Карасева М.В. Финансовое право. Общая часть: учебник / М.В. Карасева.-М.: Юрист, 2000.

13. Надежин Н.Н. Участие небанковских кредитных организаций в гражданском обороте: научно-практическое пособие / Н.Н. Надежин.-Белгород: ООНИ и РИД БелЮИ МВД России, 2007.

14. Прозоров А.Л. Финансовое право: учебник / А.Л. Прозоров; под ред. О. Н. Горбуновой.-2-е изд., перераб. и доп.-М.: Юрист, 2001.

\section{References (transliterated):}

1. Kodeks Rossiiskoi Federatsii ob administrativnykh pravonarusheniyakh ot 30 dekabrya 2001 g. № 195 -FZ // Sobranie zakonodatel'stva Rossiiskoi Federatsii. 2002. № 1 (chast' I). St. 1.

2. Federal'nyi zakon ot 10 iyulya 2002 g. № 86-FZ «0 Tsentral'nom banke Rossiiskoi Federatsii (Banke Rossii)» // Sobranie zakonodatel'stva Rossiiskoi Federatsii. 2002. № 28. St. 2790.

3. Prikaz TsB Rossiiskoi Federatsii ot 31 marta 1997 g. № $02-139$ «0 vvedenii v deistvie instruktsii «0 primenenii k kreditnym organizatsiyam mer vozdeistviya za narusheniya prudentsial'nykh norm deyatel'nosti» // Vestnik Banka Rossii. 1997. № 23(186).

4. Ukazanie operativnogo kharaktera TsB Rossiiskoi Federatsii ot 2 iyulya 2002 g. № 84-T «0 Kodekse Rossiiskoi Federatsii ob administrativnykh pravonarusheniyakh» // Vestnik Banka Rossii. 2002. № 38.

5. Postanovlenie Federal'nogo arbitrazhnogo suda Moskovskogo okruga ot 28 oktyabrya 2003 g. № KA-A40/8495-03 // Sudebno-arbitrazhnaya praktika Moskovskogo regiona. Voprosy pravoprimeneniya. 2004. № 2.

6. Postanovlenie Federal'nogo arbitrazhnogo suda Ural'skogo okruga ot 17 noyabrya 2010 g. № F09-9362/10-S.

7. Postanovlenie Federal'nogo arbitrazhnogo suda Dal'nevostochnogo okruga ot 12 aprelya 2011 g. № F03-9261/10.

8. Arslanbekova A.Z. Sootnoshenie finansovo-pravovoi i administrativno-pravovoi otvetstvennosti, primenyaemoi za narushenie bankovskogo zakonodatel'stva // Zakonodatel'stvo. 2010. № 1.

9. Veremeenko I.I. K voprosu o finansovo-pravovoi i administrativno-pravovoi otvetstvennosti v rossiiskom prave // Pravo i upravlenie. XXI vek. 2012. № 4.

10. Dem'yanets M.V. Administrativnaya otvetstvennost' kreditnykh organizatsii za narushenie zakonodatel'stva o bankakh i bankovskoi deyatel'nosti: Monografiya. - M., 2011.

11. Eropkin M.I. O klassifikatsii mer administrativnogo prinuzhdeniya // Voprosy sovetskogo administrativnogo prava na sovremennom etape. M., 1963.

12. Karaseva M.V. Finansovoe pravo. Obshchaya chast': uchebnik / M.V. Karaseva.-M.: Yurist, 2000.

13. Nadezhin N.N.Uchastie nebankovskikh kreditnykh organizatsiiv grazhdanskom oborote: nauchno-prakticheskoe posobie / N.N. Nadezhin.-Belgorod: OONI i RID BelYuI MVD Rossii, 2007.

14. Prozorov A.L. Finansovoe pravo: uchebnik / A.L. Prozorov; pod red. O. N. Gorbunovoi.-2-e izd., pererab. i dop.-M.: Yurist, 2001. 